\title{
Cinética e parâmetros de fermentação ruminal in vitro de silagens de parte aérea e raízes de mandioca
}

[Kinetic parameters and in vitro rumen fermentation of cassava foliage and roots silages]

\author{
C.F.P.G. Silva ${ }^{1,6}$, M.P. Figueiredo², M.S. Pedreira ${ }^{2}$, F.S. Bernardino ${ }^{3}$, \\ D.H. Farias ${ }^{4}$, J.A.G. Azêvedo \\ ${ }^{1}$ Aluna de pós-graduação - Universidade Estadual do Sudoeste da Bahia - Santa Inês, BA \\ ${ }^{2}$ Universidade Estadual do Sudoeste da Bahia - Itapetinga, BA \\ ${ }^{3}$ Universidade Federal de Viçosa - Viçosa, MG \\ ${ }^{4}$ Universidade Federal de Pelotas - Pelotas, RS \\ ${ }^{5}$ Universidade Estadual de Santa Cruz - Ilhéus, BA \\ ${ }^{6}$ Instituto Federal Baiano - Santa Inês, BA
}

\begin{abstract}
RESUMO
Foram avaliados os efeitos do emurchecimento e da inclusão de raízes $0,15,30$ e $45 \%$ da matéria natural sobre a cinética e os parâmetros da fermentação ruminal de silagens da parte aérea da mandioca. A produção acumulada de gases (PAG) às 96 horas de incubação foi influenciada significativamente $(\mathrm{P}<0,05)$ pela interação emurchecimento versus inclusão de raízes. Para a PAG, houve elevação linear de $1,88 \mathrm{~mL}$ a cada unidade percentual de raiz adicionada às silagens não emurchecidas e efeito quadrático nas silagens emurchecidas, com produção máxima de $226 \mathrm{~mL}$ de gases, com a inclusão de $30,5 \%$ de raízes. A degradabilidade verdadeira in vitro da MS (DVIMS) das silagens apresentou significância $(\mathrm{P}<0,05)$ para o emurchecimento e para a interação inclusão de raízes versus tempo de incubação. $\mathrm{O}$ emurchecimento reduziu, aproximadamente, $2 \%$ da degradabilidade da silagem, enquanto a inclusão de raízes propiciou elevação linear dessa variável, que atingiu o valor máximo às 24 horas de incubação.
\end{abstract}

Palavras-chave: degradabilidade, produção de gases, ruminantes, volumosos

\section{ABSTRACT}

The effects of wilting and roots inclusion $(0,15,30$ and $45 \%$ fresh matter) on rumen fermentation kinetics and parameters of cassava foliage silages were evaluated. Total gas production (TGP) after 96 hours of incubation was significantly influenced $(P<0.05)$ by the interaction between wilting and roots inclusion. $T G P$ was linearly increased by $1.88 \mathrm{~mL}$ for each percent unit of root added to the wilted silage, whereas, for wilted ones, a quadratic effect was observed, with a maximum gas cumulative output of $226 \mathrm{~mL}$ for $30.5 \%$ roots addition. The true DM degradability of silages in vitro (IVTDMD) showed significance $(P<0.05)$ to wilting and interaction between root inclusion and incubation time. Wilting reduced silage degradability in approximately $2 \%$, while root inclusion led to linear increases in this variable, which reached its peak at $24 \mathrm{~h}$ of incubation.

Keywords: degradability, gas production, ruminants, forages

\section{INTRODUÇÃO}

A redução de custos com a alimentação na pecuária tem sido enfoque das pesquisas em produção de ruminantes, sendo a utilização de coprodutos e alimentos regionais uma importante alternativa. A mandioca (Manihot esculenta,
Crantz) é uma cultura bastante difundida no país, principalmente na região Nordeste, adaptando-se bem às condições adversas do semiárido. Apresenta bom valor nutricional e alta produtividade, bem como concentração proteica superior à maioria dos volumosos de boa qualidade utilizados na alimentação de vacas

Recebido em 11 de agosto de 2011

Aceito em 20 de julho de 2012

E-mail: kmillaf@yahoo.com.br 
leiteiras especializadas A parte aérea da mandioca (PAM) é subaproveitada, sendo geralmente desprezada por ocasião da colheita das raízes. Estas concentram alto conteúdo energético e elevada digestibilidade. Tanto as raízes quanto a parte aérea da mandioca têm potencial para serem ensiladas, entretanto a ensilagem conjunta dessas fontes não foi estudada, necessitando de avaliações que comprovem seu valor nutritivo e potencialidade para serem utilizadas como silagem na alimentação de ruminantes.

O valor nutritivo dos alimentos mantém relação direta com sua digestibilidade e o desempenho dos animais. Tais determinações podem ser obtidas por métodos in vivo, in situ ou in vitro (Maurício et al., 1999; Maurício et al., 2003). De acordo com Ørskov (2002), citado por Maurício et al. (2003), as metodologias in vitro apresentam alta correlação entre consumo e digestibilidade in vivo, constituindo-se alternativas válidas na avaliação da qualidade nutricional de forrageiras. Makkar (2005) destacou ainda a importância dessas técnicas pela minimização dos custos, possibilidade de avaliação de maior número de amostras, menor tempo necessário e maior controle das condições ambientais em relação aos experimentos in vivo.

Por meio da simulação do ambiente ruminal e da digestão microbiana, a técnica semi-automática de produção de gases permite a descrição da cinética de fermentação ruminal, fornecendo informações sobre a taxa e a extensão da degradação das forrageiras (Getachew et al., 1998; Maurício et al., 2003), podendo ser útil nas estimativas de consumo (Blümmel e Ørskov, 1993). A produção de gases (PG) apresenta elevada correlação com as degradabilidades aparente e verdadeira in vitro, bem como com a degradabilidade ruminal in vivo (Blümmel et al., 1997). Os gases mensurados por meio da técnica semiautomática de produção de gás são oriundos da fermentação microbiana dos carboidratos e, em menor escala, de proteínas, representando o produto final do metabolismo energético, responsável pela produção de ATP para o crescimento e a manutenção das células microbianas (Makkar, 2002).

A produção de gases é influenciada pela composição dos alimentos, de forma que a fermentação de alimentos ricos em fibra, celulose e hemicelulose resulta proporcionalmente em maior produção de gases em relação àqueles ricos em amido, devido à diferente relação acetato:propionato entre esses substratos (Nogueira et al., 2006)

Objetivou-se com este trabalho avaliar o efeito do emurchecimento da parte aérea e da inclusão de raízes sobre a qualidade nutricional das silagens de mandioca, por meio da avaliação cinética e dos parâmetros de fermentação ruminal in vitro.

\section{MATERIAL E MÉTODOS}

Utilizou-se um delineamento inteiramente ao acaso, disposto em arranjo fatorial $2 \times 4$, sendo duas condições de umidade da parte aérea da mandioca (PAM) - com e sem emurchecimento - e quatro doses de inclusão de raízes de mandioca - 0, 15, 30 e $45 \%$, com base na matéria natural, com três repetições.

A PAM foi obtida 150 dias após o último corte. Após a colheita, o material foi processado para obter o tamanho de partícula de $2-5 \mathrm{~cm}$. As raízes de mandioca foram adquiridas no mercado local, e picadas. Em seguida, a PAM sem emurchecimento foi acrescida pelas devidas proporções de raízes e imediatamente ensilada. A outra parte da PAM foi submetida à secagem natural durante quatro horas (emurchecimento); após esse período, procedeu-se à inclusão das raízes e efetuou-se a ensilagem. $\mathrm{O}$ material foi ensilado em minissilos experimentais de policloreto de vinil (PVC), com $50 \mathrm{~cm}$ de altura e $20 \mathrm{~cm}$ de diâmetro, dotados de válvulas de Bunsen. A compactação do material foi realizada manualmente com bastão de madeira. Após a acomodação final do material, os silos foram devidamente fechados e vedados com fitas adesivas, pesados e acondicionados em local fresco e arejado até o momento da abertura, 90 dias após a ensilagem.

A técnica de produção de gases in vitro foi conduzida de acordo com o descrito por Maurício et al. (1999). Em frascos de $160 \mathrm{~mL}$ foram adicionados $\mathrm{CO}_{2}$ e $1 \mathrm{~g}$ das amostras $(1 \mathrm{~mm})$, com uma réplica para cada silagem de PAM - com e sem emurchecimento - e raízes de mandioca $-0,15,30$ e $45 \%$ (Tab. 1 ). 
Cinética e parâmetros...

Tabela 1. Composição química de silagens da parte aérea e raízes de mandioca

\begin{tabular}{|c|c|c|c|c|c|c|}
\hline \multirow{2}{*}{ Item } & \multirow{2}{*}{ Trat. } & \multicolumn{4}{|c|}{ Inclusão de raízes (\% MN) } & \multirow{2}{*}{ Média } \\
\hline & & 0 & 15 & 30 & 45 & \\
\hline \multirow{2}{*}{ MS, \% } & PAM1 & $12,59 \mathrm{~b}$ & $16,53 b$ & $21,98 b$ & $23,88 b$ & 18,75 \\
\hline & PAM2 & $20,21 \mathrm{a}$ & $24,18 \mathrm{a}$ & $24,61 \mathrm{a}$ & $26,48 \mathrm{a}$ & 23,87 \\
\hline \multirow{2}{*}{ MM, \%MS } & PAM1 & $7,92 \mathrm{a}$ & $6,20 \mathrm{a}$ & $5,10 \mathrm{a}$ & $4,14 \mathrm{a}$ & 5,84 \\
\hline & PAM2 & $7,37 b$ & $6,43 \mathrm{a}$ & $4,98 \mathrm{a}$ & $3,89 \mathrm{a}$ & 5,67 \\
\hline \multirow{2}{*}{$\mathrm{PB}, \% \mathrm{MS}$} & PAM1 & $18,01 b$ & $14,21 b$ & $11,36 b$ & $8,99 \mathrm{~b}$ & 13,14 \\
\hline & PAM2 & $20,90 \mathrm{a}$ & $18,50 \mathrm{a}$ & $15,06 \mathrm{a}$ & $11,03 \mathrm{a}$ & 16,37 \\
\hline \multirow{2}{*}{ PIDN, \% MS } & PAM1 & $5,45 \mathrm{a}$ & $2,30 \mathrm{~b}$ & $1,72 b$ & $1,27 \mathrm{a}$ & 2,69 \\
\hline & PAM2 & $5,29 a$ & $3,17 \mathrm{a}$ & $2,60 \mathrm{a}$ & $1,52 \mathrm{a}$ & 3,15 \\
\hline \multirow{2}{*}{ PIDA, \% MS } & PAM1 & $2,56 a$ & $1,60 \mathrm{a}$ & $1,21 \mathrm{a}$ & $0,58 b$ & 1,49 \\
\hline & PAM2 & $2,03 b$ & $1,63 \mathrm{a}$ & $1,17 \mathrm{a}$ & $0,82 \mathrm{a}$ & 1,41 \\
\hline \multirow{2}{*}{ FDN, \%MS } & PAM1 & $51,03 \mathrm{a}$ & $36,60 \mathrm{a}$ & $26,38 b$ & $19,74 a$ & 33,44 \\
\hline & PAM2 & $49,04 a$ & $37,80 \mathrm{a}$ & $29,49 a$ & $21,35 \mathrm{a}$ & 34,42 \\
\hline \multirow{2}{*}{ FDA, \%MS } & PAM1 & 40,74 & 30,76 & 23,13 & 16,81 & $27,86 b$ \\
\hline & PAM2 & 40,81 & 32,54 & 23,72 & 19,64 & $29,18 \mathrm{a}$ \\
\hline \multirow{2}{*}{ HEM, \%MS } & PAM1 & $10,29 a$ & $5,84 \mathrm{a}$ & $3,25 \mathrm{a}$ & $2,93 \mathrm{a}$ & 5,58 \\
\hline & PAM2 & $8,23 b$ & $3,25 \mathrm{a}$ & $2,93 b$ & $1,71 \mathrm{a}$ & 4,03 \\
\hline \multirow{2}{*}{ LIG, \%MS } & PAM1 & 12,37 & 8,63 & 6,67 & 4,84 & $8,13 b$ \\
\hline & PAM2 & 13,51 & 9,48 & 8,50 & 5,81 & $9,33 \mathrm{a}$ \\
\hline \multirow{2}{*}{$\mathrm{CT}, \% \mathrm{MS}$} & PAM1 & $70,91 \mathrm{a}$ & $77,56 a$ & $81,47 \mathrm{a}$ & $85,21 \mathrm{a}$ & 78,79 \\
\hline & PAM2 & $67,68 b$ & $72,21 b$ & $77,07 \mathrm{~b}$ & $83,11 b$ & 75,02 \\
\hline \multirow{2}{*}{$\mathrm{CNF}, \% \mathrm{MS}$} & PAM1 & $25,08 \mathrm{a}$ & $44,75 \mathrm{a}$ & $58,13 \mathrm{a}$ & $67,88 \mathrm{a}$ & 48,96 \\
\hline & PAM2 & $23,93 \mathrm{a}$ & $38,77 \mathrm{~b}$ & $51,11 \mathrm{~b}$ & $64,41 b$ & 44,56 \\
\hline \multirow{2}{*}{ NDT, $\% \mathrm{MS}$} & PAM1 & 53,28 & 62,87 & 69,67 & 74,61 & $65,11 \mathrm{a}$ \\
\hline & PAM2 & 52,18 & 62,56 & 67,31 & 72,84 & $63,72 b$ \\
\hline
\end{tabular}

*Letras distintas na mesma coluna indicam diferença entre valores entre si a $5 \%$ de probabilidade pelo teste " $\mathrm{t}$ " de Student $(\mathrm{P}<0,05)$. MS, matéria seca; MM, matéria mineral; $\mathrm{PB}$, proteína bruta; PIDN, proteína insolúvel em detergente neutro; PIDA, proteína insolúvel em detergente ácido; HEM, hemicelulose; LIG, lignina; CT, carboidratos totais; CNF, carboidratos não fibrosos; NDT, nutrientes digestíveis totais. PAM 2 e 1: parte aérea da mandioca submetida ou não ao emurchecimento.

Em cada frasco foram adicionados $90 \mathrm{~mL}$ de meio de cultura contendo minerais e tamponantes (Theodorou et al., 1994). As soluções foram preparadas na noite antecedente à incubação e mantidas em estufa a $39^{\circ} \mathrm{C}$.

O inóculo ruminal utilizado na inoculação foi composto por uma mistura dos fluidos ruminais de três vacas da raça Holandesa, portadoras de cânulas no rúmen, mantidas em confinamento, cuja dieta foi composta por silagem de capimelefante com casca de café ad libitum, 3,8kg de mistura de alimentos concentrados contendo milho moído e farelo de soja, sal mineral e água.

As vacas foram mantidas em jejum hídrico e alimentar nas 12 horas que antecederam a coleta do fluido. Após a coleta, o fluido foi armazenado em garrafas térmicas para transporte até o laboratório, onde foi filtrado em tecido de nylon com porosidade de $100 \mu \mathrm{m}$, misturados nas mesmas proporções e saturados com $\mathrm{CO}_{2}$, enquanto mantidos em banho-maria a $39^{\circ} \mathrm{C}$. O fluido ruminal $(10 \mathrm{~mL})$ foi inoculado nos frascos contendo amostras e meio de cultura; estes foram vedados com tampas de borracha expansivas e mantidos em estufa $\left(39^{\circ} \mathrm{C}\right)$ até o momento das leituras.

As leituras de pressão dos gases produzidos durante as fermentações foram realizadas às duas, quatro, seis, oito, 10, 12, 15, 18, 21, 24, 30, 36, 48, 72 e 96 horas após o início das incubações. As leituras de pressão dos gases (PSI; pressão por polegada quadrada) foram realizadas de forma semiautomática, por meio de um transdutor de pressão (tipo T443A, Bailey e Mackey, Inglaterra). As medidas de pressão obtidas foram ajustadas para o volume de gases conforme a equação proposta por Figueiredo et 
al. (2003), para a altitude local (Vitória da Conquista-BA): $\mathrm{V}=-0,02+4,30 \mathrm{p}+0,07 \mathrm{p}^{2}$, em que $\mathrm{V}$ é o volume dos gases $(\mathrm{mL})$ e p é a pressão dos gases dentro dos frascos de fermentação (PSI).

A degradação verdadeira in vitro das silagens foi determinada seis, 12, 24, 48 e 96 horas após a inoculação. A degradabilidade ruminal foi estimada como a diferença entre a quantidade de amostra colocada para fermentar em cada frasco e a quantidade de resíduo recuperado após digestão com solução detergente neutro por uma hora; em seguida, filtrado em cadinho de vidro $\mathrm{n}^{\circ}$ 1 e seco em estufa a $105^{\circ} \mathrm{C}$ por 24 horas (Goering e Van Soest, 1970).

A cinética da produção cumulativa de gases foi avaliada empregando-se o modelo logístico bicompartimental para a estimativa dos seus parâmetros (Schofield et al., 1994): $\mathrm{V}(\mathrm{t})=$ $(\mathrm{Vf} 1 /(1+\exp (2-4 * \mathrm{Kd} 1 *(\mathrm{~T}-\mathrm{L})))+(\mathrm{Vf} 2 /(1+\exp (2-$ $4 * \mathrm{Kd} 2 *(\mathrm{~T}-\mathrm{L})))$, em que $\mathrm{V}(\mathrm{t})$ é o volume acumulado no tempo t; Vf1, o volume de gás oriundo da fração de rápida digestão (CNF); $\operatorname{Kd} 1\left(\mathrm{~h}^{-1}\right)$, a taxa de degradação da fração de rápida digestão (CNF); L, a latência ou o tempo de colonização em horas; T, o tempo (h); Vf2, o volume de gás da fração de lenta degradação (B2); Kd2 $\left(\mathrm{h}^{-1}\right)$, a taxa de degradação da fração B2.

Utilizou-se um delineamento inteiramente ao acaso, composto de três repetições, em que cada repetição do silo foi incubada em uma rodada distinta. Os dados foram submetidos à análise de variância utilizando-se programa estatístico SAS (Statistical Analysis Sistem, 2006). Para estudo detalhado da interação emurchecimento da parte aérea versus porcentagem de inclusão de raiz, quando esta foi significativa, foram realizados os desdobramentos adequados. Para o estudo do efeito do emurchecimento, aplicou-se o teste de Tukey a 5\% de significância e, de outro modo, o efeito crescente da inclusão de raiz em cada umidade da PAM (com e sem emurchecimento), aplicou-se a análise de regressão, sendo a escolha do modelo baseada na significância dos parâmetros testados pelo teste $\mathrm{t}$ de Student e nos valores dos coeficientes de determinação.

Para a variável degradabilidade verdadeira da MS, foi considerado o efeito do tempo de incubação, em um esquema de análise de parcelas subdivididas no tempo: zero, seis, 12 , 24, 48 e 96 horas, split-splot no tempo, utilizando-se a análise de regressão polinomial superfície de resposta -, para estudar a influência do tempo de incubação e da porcentagem de inclusão de raízes.

\section{RESULTADOS E DISCUSSÃO}

A produção acumulada de gases (PAG) às 96h de incubação apresentou interação significativa $(\mathrm{P}<0,05)$ entre o emurchecimento e a inclusão de raízes (Tab. 2). Quanto ao efeito do emurchecimento dentro da inclusão de raízes, constatou-se que este afetou a produção de gases apenas com 30 e $45 \%$ de inclusão, apresentando efeito positivo no primeiro e negativo no segundo.

Tabela 2. Produção acumulada de gases (PAG; mL) de silagens da parte aérea da mandioca com (U2) e sem emurchecimento (U1) em razão da inclusão de raízes durante $96 \mathrm{~h}$ de incubação in vitro

\begin{tabular}{|c|c|c|c|c|c|c|c|c|}
\hline \multirow{2}{*}{ PAM* } & \multicolumn{4}{|c|}{ Inclusão de raiz (\% MN) } & \multirow{2}{*}{$\begin{array}{l}\text { CV } \\
(\%)\end{array}$} & \multicolumn{3}{|c|}{ Efeito } \\
\hline & 0 & 15 & 30 & 45 & & $\mathrm{U}$ & $\mathrm{R}$ & UxR \\
\hline \multicolumn{9}{|c|}{ PAG (96h) } \\
\hline U1 & $144,0 \mathrm{a}$ & $204,1 \mathrm{a}$ & $172,2 b$ & $249,0 \mathrm{a}$ & 17,28 & \multirow{2}{*}{ ns } & \multirow{2}{*}{$*$} & \multirow{2}{*}{$*$} \\
\hline $\mathrm{U} 2$ & $125,8 \mathrm{a}$ & $190,3 \mathrm{a}$ & $235,5 \mathrm{a}$ & $199,8 b$ & 13,18 & & & \\
\hline
\end{tabular}

PAM, parte aérea da mandioca.

Médias seguidas de letras iguais na coluna não diferem entre si a 5\% de probabilidade pelo teste de Tukey.

Ao se avaliar a PAG em razão da adição de raízes (Tab. 3), verificou-se que nas silagens não emurchecidas houve elevação linear de $1,88 \mathrm{~mL}$ a cada unidade de raiz adicionada. Em relação às silagens emurchecidas, a análise da regressão revelou comportamento quadrático, obtendo-se produção máxima de $226 \mathrm{~mL}$ de gases com a inclusão de $30,5 \%$ de raízes.

As silagens não acrescidas de raízes apresentaram os menores valores de produção de gases $(144,0$ e $125,8 \mathrm{~mL})$ em relação aos demais 
substratos contendo raízes, o que pode ser atribuído à menor proporção de carboidratos não fibrosos (CNF) e elevado teor de proteína bruta (Tab. 1). Os CNF apresentam maior taxa de fermentação no rúmen e contribuem significativamente para a produção de ácidos graxos voláteis (AGVs). Além disso, de acordo com Khazaal et al. (1995), a incubação de substratos ricos em proteína resultaria na formação de bicarbonato de amônio, a partir de $\mathrm{CO}_{2}$ e amônia, reduzindo, assim, a contribuição de $\mathrm{CO}_{2}$ para a produção total de gás.

Tabela 3. Produção acumulada de gases (PAG; 96h) das silagens de parte aérea da mandioca em razão da inclusão de raízes

\begin{tabular}{ccc}
\hline Tratamento & Equações de regressão & $\mathrm{R}^{2}$ \\
\hline \multicolumn{3}{c}{ PAG $(96 \mathrm{~h})$} \\
PAM1 & $\hat{\mathrm{Y}}=149,867+1,8877 \mathrm{x}$ & 0,52 \\
PAM2 & $\hat{\mathrm{Y}}=122,762+6,7886 \mathrm{x}-$ & 0,77 \\
& $0,1113 \mathrm{x}^{2}$ & \\
\hline
\end{tabular}

PAM 2 e 1: parte aérea com e sem emurchecimento.

A inclusão de raízes proporcionou elevação da fração de carboidratos não fibrosos (Tab. 1), representada principalmente pelo amido, resultando em maior PAG, o que corrobora com Cabral et al. (2002), que verificaram aumento linear do volume de gases com o acréscimo de diferentes porcentagens de grãos na silagem de milho. Entretanto, Blümmel et al. (1997) afirmaram que substratos ricos em amido proporcionam maior produção de propionato, podendo resultar em menor volume total de gases quando comparados a substratos fibrosos, cuja capacidade de produção de acetato é maior, sendo, por conseguinte, a produção de gases proporcionalmente superior. Isso ocorre porque a formação do propionato é a única via metabólica na produção dos três principais AGVs, a qual consome hidrogênio e não envolve a produção de dióxido de carbono $\left(\mathrm{CO}_{2}\right)$, além de não contribuir para a formação de gases mensurados pela técnica (van Soest, 1994). A divergência encontrada entre este trabalho e o de Blümmel et al. (1997) pode estar relacionada à menor fermentabilidade da PAM, em razão dos altos teores de lignina e de proteína, ambos reduzidos com a inclusão de raízes.

Pereira et al. (2007), ao utilizarem a técnica de produção de gases, obtiveram, para silagens de milho com $41,9 \%$ de MS e 31,5\% de grãos, um volume total de gases em $96 \mathrm{~h}$ de $23,1 \mathrm{~mL} \cdot \mathrm{mg}^{-1}$ de amostra, o que equivale a $231 \mathrm{~mL} . \mathrm{g}^{-1}$, valor similar ao observado para silagens de PAM emurchecida com $30 \%$ de raízes $\left(235,4 \mathrm{~mL} \cdot \mathrm{g}^{-1}\right)$, comprovando o bom valor nutricional dessa silagem.

A degradabilidade verdadeira in vitro da MS (DVIMS) das silagens apresentou significância $(\mathrm{P}<0,05)$ para o emurchecimento e para a interação entre a inclusão de raízes e o tempo de incubação (Fig. 1). Os valores das estimativas de DVIMS para as silagens não emurchecidas se ajustaram ao modelo polinomial de regressão. Verifica-se que, no tempo zero de incubação, as silagens apresentaram valores de degradação entre 20 e 35\%, ocorrendo elevação linear dos valores à medida que se incrementou a inclusão de raízes. Estes valores expressam um alto conteúdo de compostos solúveis prontamente disponíveis no rúmen. Com o decorrer da incubação, verificou-se aumento da degradação das silagens, tendo, por volta de $24 \mathrm{~h}$, um pico de degradação em todas as silagens avaliadas, sendo de magnitude superior para as silagens com maior percentual de raízes.

A curva de degradação estimada para as silagens emurchecidas foi similar à das silagens não emurchecidas, sendo a diferença apenas relativa ao menor percentual de degradação, cerca de $2 \%$ inferior em resposta ao emurchecimento (Fig. 1). Tais resultados podem estar relacionados à diferença na proporção de raízes na MS total das silagens, já que a adição destas foi definida com base na MN. Dessa forma, as silagens emurchecidas teriam maior contribuição da PAM na MS total e, consequentemente, menor degradabilidade do que aquelas com maior proporção de raízes (silagens de PAM não emurchecidas). 

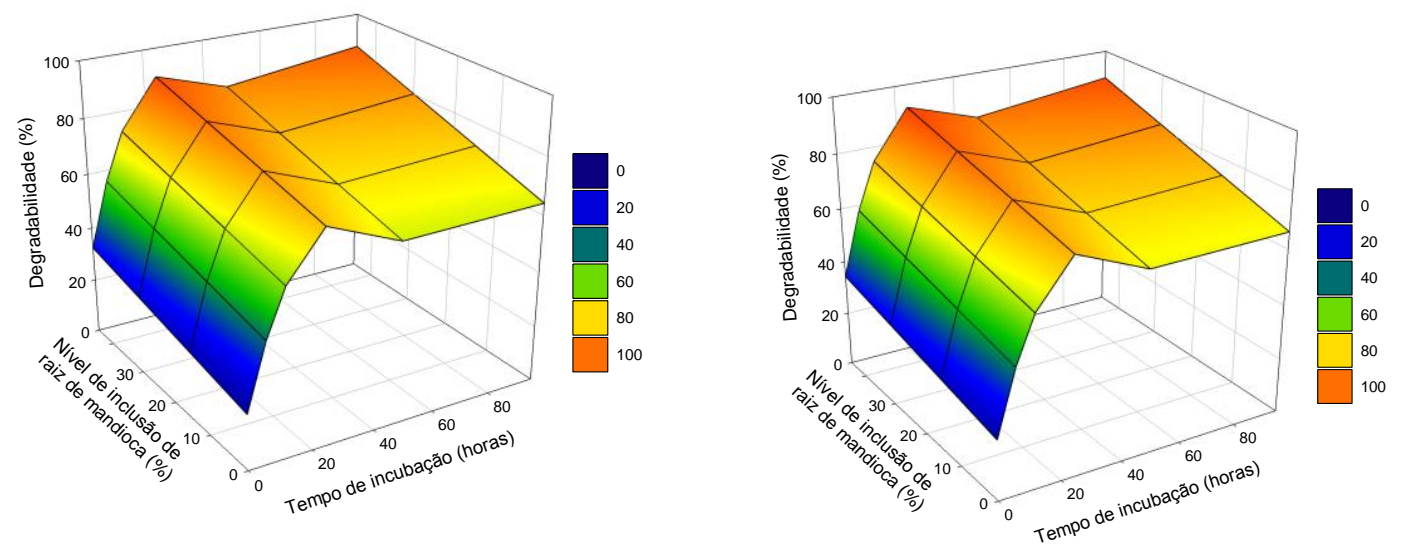

$$
\begin{gathered}
\hat{Y}=21,8019+0,2799 R+4,414 T-0,1047 T^{2}+0,00066 T^{3}+0,0026 R T \\
R^{2}=0,88
\end{gathered}
$$

Figura 1. Degradabilidade in vitro da matéria seca de silagens da parte aérea da mandioca não emurchecida (esquerda) e emurchecida (direita), em razão da inclusão de raízes (R) e do tempo de incubação $(\mathrm{T})$ ruminal in vitro/gás.

A elevada degradabilidade no tempo de $24 \mathrm{~h}$ indica que as silagens podem prover um rápido fluxo de partículas para fora do rúmen, permitindo maior ingestão de alimentos e possivelmente melhor desempenho. Velho (2005) obteve DIVMS às $24 \mathrm{~h}$ de incubação em silagens de milho com estágio de maturação leitoso e $1 / 2$ leitoso $1 / 2$ farináceo de, respectivamente, 76,9 e 77,0\%, valores próximos aos encontrados para a silagem de PAM sem inclusão de raízes, que variaram entre 74,6 e $76,6 \%$, com e sem emurchecimento. Maurício et al. (2003) encontraram resultados mais baixos para as silagens de híbridos de sorgo e capimsudão, que variaram entre 56,4 e $63,1 \%$ de degradação em $48 \mathrm{~h}$ de fermentação.

A degradabilidade das silagens ao final das $96 \mathrm{~h}$ variou entre 64,6 e $88,4 \%$ da MS nas silagens não emurchecidas e entre 62,6 e $86,4 \%$ para as silagens emurchecidas, respectivamente, para $0 \mathrm{e}$ $45 \%$ de inclusão de raízes. Resultados semelhantes foram encontrados por Cabral et al. (2002), em silagens de milho com proporção de 0 a $60 \%$ de grãos, que apresentaram DVIMS entre 62,2 e $80,6 \%$.
Para os parâmetros cinéticos Vf1 e Kd1, verificou-se significância $(P<0,05)$ para interação emurchecimento da PAM versus inclusão de raízes (Tab. 4). Ao se avaliarem os valores de Vf1 em razão do acréscimo de raízes para a silagem sem emurchecimento, nenhum modelo ajustou-se aos dados, estimando-se a média de $103,104 \mathrm{~mL} \cdot \mathrm{g}^{-1}$. Nestas silagens constatou-se maior taxa de digestão dos $\operatorname{CNF}\left(0,114 . h^{-1}\right)$ com a adição de $29,4 \%$ de raízes. Com relação à silagem emurchecida, a inclusão de raízes promoveu efeito quadrático sobre o Vf1, com produção máxima de gases de $205,67 \mathrm{~mL} \mathrm{~g}^{-1}$ observada com a adição de $26,4 \%$ de raízes de mandioca, e aumento linear do Kd1 (Tab. 4).

As taxas de digestão estimadas para os CNF nas silagens com maior participação de raízes estão de acordo com os limites de 10 a $40 \% \cdot \mathrm{h}^{-1}$ sugeridos por Sniffen et al. (1992) para a fração B1 dos carboidratos. Todavia, as silagens com menores percentuais de raízes, 0 e $15 \%$, apresentaram taxas de digestão dos $\mathrm{CNF}$ mais baixos, o que provavelmente está relacionado à natureza desses carboidratos, predominantemente ácidos orgânicos, compostos que não são fermentados no rúmen. 
Tabela 4. Estimativas dos parâmetros cinéticos da produção de gases in vitro da matéria seca (MS) das silagens de parte aérea com (U2) e sem emurchecimento (U1) e raízes de mandioca

\begin{tabular}{|c|c|c|c|c|c|c|c|}
\hline \multirow[b]{2}{*}{ PAM } & \multicolumn{4}{|c|}{ Inclusão de raiz (\% MN) } & \multirow{2}{*}{$\begin{array}{l}\text { CV } \\
(\%)\end{array}$} & \multirow{2}{*}{ Equação de regressão } & \multirow{2}{*}{$\mathrm{R}^{2}$} \\
\hline & 0 & 15 & 30 & 45 & & & \\
\hline \multicolumn{8}{|c|}{ Vf1 $\left(\mathrm{mL} \cdot \mathrm{g}^{-1}\right)$} \\
\hline U1 & 78,6 & 126,0 & 74,2 & 133,6 & & $\hat{Y}=103,104$ & - \\
\hline $\mathrm{U} 2$ & 66,2 & 113,9 & 140,9 & 97,1 & 19,23 & $\hat{Y}=63,656+5,375 x-0,1017 x^{2}$ & 69,5 \\
\hline \multicolumn{8}{|c|}{$\operatorname{Kd} 1\left(h^{-1}\right)$} \\
\hline U1 & 0,084 & 0,09 & 0,125 & 0,094 & & $\hat{Y}=0,0793+0,00235 x-0,00004 x^{2}$ & 51,5 \\
\hline $\mathrm{U} 2$ & 0,077 & 0,09 & 0,090 & 0,116 & 11,49 & $\hat{\mathrm{Y}}=0,0761+0,000767 \mathrm{x}$ & 50,3 \\
\hline \multicolumn{8}{|c|}{$\mathrm{L}(\mathrm{h})$} \\
\hline U1 & 7,58 & 8,00 & 7,83 & 8,72 & & $\hat{Y}=8,03$ & - \\
\hline $\mathrm{U} 2$ & 8,01 & 7,40 & 7,69 & 8,47 & 4,45 & $\hat{\mathrm{Y}}=7,89$ & - \\
\hline \multicolumn{8}{|c|}{$\mathrm{Vf} 2\left(\mathrm{~mL} \cdot \mathrm{g}^{-1}\right)$} \\
\hline U1 & 62,7 & 74,5 & 94,0 & 110,0 & & $\hat{Y}=61,1054+1,076 x$ & 75,6 \\
\hline $\mathrm{U} 2$ & 56,7 & 72,5 & 90,0 & 99,0 & $1 /, 21$ & $\hat{Y}=57,9147+0,9623 x$ & 60,5 \\
\hline \multicolumn{8}{|c|}{$\mathrm{Kd} 2\left(\mathrm{~h}^{-1}\right)$} \\
\hline U1 & 0,025 & 0,026 & 0,028 & 0,027 & 795 & $\hat{Y}=0,0245+0,00019 x-0,000003 x^{2}$ & 51,1 \\
\hline $\mathbf{U} 2$ & 0,022 & 0,023 & 0,026 & 0,027 & 1,95 & $\hat{\mathrm{Y}}=0,0221+0,000104 \mathrm{x}$ & 38,5 \\
\hline
\end{tabular}

Vf1= volume máximo de produção de gases da fração dos CNF; Kd1= taxa de digestão para a fração dos CNF; $\mathrm{L}=$ tempo de colonização; Vf2= volume máximo da produção de gases da fração dos $\mathrm{CF} ; \mathrm{Kd} 2=$ taxa de digestão para a fração dos CF..

Cabral et al. (2002), ao avaliarem a melhora da qualidade nutricional de silagem de milho da planta inteira mediante o incremento de grãos, também verificaram aumento dos CNF e redução dos $\mathrm{CF}$, o que propiciou maior produção de gases e degradabilidade dos nutrientes. Entretanto, as taxas de digestão (Kd1 e $\mathrm{Kd} 2$ ) foram afetadas quadraticamente, de forma similar ao ocorrido no presente trabalho. Segundo esses mesmos autores, em sistemas in vitro, a alteração dos parâmetros cinéticos pode ser atribuída ao acúmulo de metabólitos (AGVs) em taxas elevadas ao ambiente de incubação ou mesmo à exaustão dos nutrientes $(\mathrm{N})$, que pode inibir a ação fermentativa, mesmo que ainda existam nutrientes potencialmente digestíveis. Tal explicação pode ser a base para os resultados observados neste estudo em relação aos parâmetros cinéticos Vf1 e Kd1, uma vez que a maior inclusão de raízes aumentou a disponibilidade de carboidratos de fácil digestão, favorecendo o acúmulo de gases, mas, por outro lado, diminuiu o aporte de nitrogênio, o que pode ter influído na atividade microbiana.

Os tempos de colonização (L) das silagens foram significativamente afetados $(\mathrm{P}<0,05)$ pela inclusão de raízes, entretanto nenhum modelo se ajustou adequadamente aos dados, estimando-se uma média de 8,03 e 7,49h, respectivamente, para as silagens de PAM sem e com emurchecimento.

O tempo de colonização (L) representa o tempo entre o início da incubação e a ação microbiana sobre o substrato testado. Essa característica está relacionada à presença de substratos prontamente fermentescíveis e às propriedades físicas e químicas (antinutrientes) da amostra, capazes de facilitar a fermentação microbiana. As silagens avaliadas apresentaram altos valores de L, mesmo naquelas acrescidas com maior percentual de raízes, cujo conteúdo de CNF foi alto e o de lignina baixo (Tab. 1). Uma das possíveis explicações seria a inespecificidade microbiana do inóculo ruminal em relação ao substrato, uma vez que os animais doadores não foram alimentados com as silagens em estudo, dificultando a colonização e a fermentação inicial do substrato. Schofield e Pell (1995) verificaram diferenças significativas nos parâmetros cinéticos, ao usarem diferentes inóculos de líquido ruminal, e relataram que as diferenças encontradas podem ter ocorrido em razão de diferentes quantidades e espécies de microrganismos no inóculo.

Tomich et al. (2003), ao avaliarem sorgo e híbridos de sorgo e capim-sudão, não encontraram diferença estatística para valores de $\mathrm{L}$, que variaram de $2 \mathrm{~h}$ e $6 \mathrm{~min}$ a $3 \mathrm{~h}$ e $30 \mathrm{~min}$. 
Campos et al. (2000) encontraram, para silagens de milho com diferentes teores de MS, taxas de colonização entre 5,6 e 7,6h, estando mais próximos dos resultados observados para as silagens avaliadas (Tab. 4). Entretanto, os valores de $\mathrm{L}$ obtidos nesta pesquisa foram mais baixos que os relatados para gramíneas tropicais, conforme Sá (2007) para Brachiaria bryzantha cv. Marandu, em diferentes idades de crescimento, média de 15,6h, e Malafaia (1997) para capim-elefante, capim-gordura, Brachiaria bryzantha e Brachiaria decumbens, com valores de L de, respectivamente, 8,5, 12,2, 10,4 e 8,1h.

A inclusão de raízes influenciou positivamente $(\mathrm{P}<0,05)$ os valores de Vf2 das silagens sem e com emurchecimento (Tab. 4), sendo estimados acréscimos de 1,07 e $0,96 \mathrm{~mL}$ de gases.g ${ }^{-1}$, respectivamente, para cada unidade adicionada. Para as taxas de digestão da fração fibrosa $(\mathrm{Kd} 2)$, houve efeito da porcentagem de raízes $(\mathrm{P}<0,05)$ e do emurchecimento $(\mathrm{P}<0,05)$. Nas silagens não emurchecidas, à análise de regressão, estimou-se uma equação de segundo grau para representar o efeito da inclusão de raízes sobre a $\mathrm{Kd} 2$, sendo a taxa máxima de digestão obtida pelo acréscimo de $31,67 \%$ de raízes. Já nas silagens emurchecidas, verificou-se efeito linear crescente sobre a variável supracitada com o aumento da participação das raízes.

Embora o incremento na proporção de raízes às silagens tenha promovido decréscimo no teor de $\mathrm{CF}$, maiores volumes de gases foram produzidos pela fermentação desta fração. Conforme Cabral et al. (2002), concentrações moderadas de carboidratos de rápida fermentação podem estimular a degradação da fibra, fato que parece ter ocorrido neste trabalho.

Modesto et al. (2004), ao avaliarem silagens do terço superior da rama da mandioca, obtiveram, para Kd1 e $\mathrm{Kd} 2, \quad 0,123$ e $0,025 . \mathrm{h}^{-1}$, respectivamente. Valor similar de $\mathrm{Kd} 2(0,025 . \mathrm{h}$ ${ }^{1}$ ) foi obtido neste estudo para a silagem de PAM sem acréscimo de raízes, porém inferior para a $\operatorname{Kd} 1\left(0,084 \cdot h^{-1}\right)$. Ambos os estudos apresentaram valores aquém dos relatados por Campos et al. (2000) para a Kd2 em silagem de milho e feno de alfafa, respectivamente, 0,042 e $0,037 . \mathrm{h}^{-1}$, mas foram ligeiramente mais altos que os obtidos para sorgo e híbridos de sorgo e capim-sudão, observados por Tomich et al. (2003). A menor taxa de digestão da fração fibrosa da silagem da PAM é provavelmente devido à elevada concentração de lignina em sua FDN, o que limita o acesso microbiano, retardando a degradação dos compostos da parede celular.

Tomich et al. (2003) ressaltaram a importância dos parâmetros cinéticos como critério de seleção ou avaliação da qualidade das forragens, não devendo, contudo ser levados em consideração individualmente, pois maiores Vf1 e Vf2 indicam maior fermentabilidade do material, sem considerar a limitação do tempo de permanência do alimento no rúmen, enquanto os altos valores de $\mathrm{Kd} 1 \mathrm{e} \mathrm{Kd} 2$ implicam menor tempo de degradação para as frações potencialmente fermentescíveis, mas desconsideram a extensão desta fração no alimento. Neste sentido, forragens mais fermentescíveis, ou digestíveis, seriam aquelas que apresentam altos valores de potencial máximo e taxa de produção de gases, pois alcançariam potenciais máximos de fermentação em menor tempo.

A cinética de digestão e de passagem do alimento pode prover dados sobre a eficiência de utilização dos alimentos, fornecendo parâmetros importantes para avaliação e seleção dos alimentos. Maiores taxas de degradação poderão resultar em aumento da velocidade de fluxo da digesta, elevando a ingestão de MS e a quantidade de substratos disponíveis para a biossíntese microbiana, o que acarretará maior oferta de PB no intestino delgado e, por conseguinte, melhor desempenho animal.

\section{CONCLUSÃO}

$\mathrm{O}$ emurchecimento afeta negativamente a produção de gases e a degradabilidade da matéria seca. A inclusão de raízes melhora as características de fermentação ruminal in vitro das silagens da parte aérea da mandioca, aumentando a disponibilidade de nutrientes digestíveis e de energia, o que favorece a degradação da MS. 


\section{REFERÊNCIAS}

BLÜMMEL, M.; ØRSKOV, E.R. Comparison of in vitro gas production and nylon degradability of roughage in predicting feed intake in cattle. Anim. Feed Sci. Technol., v.40, p.109-119, 1993.

BLÜMMEL, M.; STEINGAB, H.; BECKER, K. The relationship between in vitro gas production, in vitro microbial biomass yield an ${ }^{15} \mathrm{n}$ incorporation and its implications for the predition of voluntary feed intake of roughages. Br. J. Nutrit., v.77, p.911-921, 1997.

CABRAL, L.S.; VALADARES FILHO, S.C.; DETMANN, E. et al. Cinética ruminal das frações de carboidratos, produção de gás, digestibilidade in vitro da matéria seca e NDT estimado da silagem de milho com diferentes proporções de grãos. Rev. Bras. Zootec., v.31, p.2332-2339, 2002.

CAMPOS, F.P.; BOSE, M.L.V.; BOIN, C. et al. Avaliação do sistema de monitoramento computadorizado de digestão in vitro.3. Desaparecimento da matéria seca e/ou FDN pela produção de gás. Rev. Bras. Zootec., v.29, p.537-544, 2000 .

FIGUEIREDO, M.P.; MAURÍCIO, R.M.; PEREIRA, L.G.R. et al. Determinação da relação entre a pressão e volume através da fermentação da raiz de mandioca tratada com ureia, feno de tifton 85 e silagem de milho para instalação da técnica in vitro de produção de gases. In: REUNIÃO ANUAL DA SOCIEDADE BRASILEIRA DE ZOOTECNIA, 40., 2003, Santa Maria. Anais... Santa Maria, RS: [s.n.] 2003. CDROM. (resumo).

GETACHEW, G.; BLÜMMEL, M.; MAKKAR, H.P.S. et al. In vitro gas measuring techniques for assessment of nutrition quality of feeds: a review. Anim. Feed Sci. Technol., v.72, p.261-281, 1998.

GOERING, H.K.; VAN SOEST, P.J. Forage fiber analysis: apparatus, reagents, procedures, and some applications. Washington, DC: USDA, 1970. 379p.

KHAZAAL, K.; DENTINHO, M.T.; RIBEIRO, J.M. et al. Prediction of apparent digestibility and voluntary intake of hays fed to sheep: comparison between using fiber components, in vitro digestibility or characteristics of gas production or nylon bag degradation. Anim. Sci., v.61, p.527-538, 1995.

MALAFAIA, P.A.M. Taxas de digestão das frações proteicas e de carboidratos de alimentos por técnicas in situ, in vitro e de produção de gases. 1997. 85f. Tese (Doutorado em Zootecnia) - Universidade Federal de Viçosa, Viçosa.
MAKKAR, H.P.S. Applications of the in vitro gas method in the evaluation of feed resources, and enhancement of nutritional value of tannin-rich tree/browse leaves and agro-industrial by-products. In: SCIENTIFIC JOURNALS AND CONFERENCE, 1., 2002, Cairo. Proceedings... Cairo, Egypt: FAO/IAEA, division of nuclear Techniques in Food and Agriculture, 2002. p.23-42.

MAKKAR, H.P.S. Recent advances in vitro gas method for evaluation of nutritional quality of feed resources. Assessing quality and safety of animal feeds. FAO Animal Production and Health Paper 2005. 170p. Disponível em: < http://www.fao.org/docrep/007/y5159e/y5159e05.htm \#TopOfPage>. Acessado em: 12 dez. 2008.

MAURÍCIO, R.M.; MOULD, F.L.; DHANOA, M.S. A semi-automated in vitro gas production technique for ruminant feedstuff evaluation. Anim. Feed Sci. Technol., v.79, p.321-330, 1999.

MAURÍCIO, R.M.; PEREIRA, L.G.R.; GONÇALVES, L.C. et al. Relação entre pressão e volume para implantação da técnica in vitro semiautomática de produção de gases na avaliação de forrageiras tropicais. Arq. Bras. Med. Vet. Zootec., v.55, p.216-219, 2003.

MODESTO, E.C.; SANTOS, G.T.; VILELA, D. et al. Caracterização químico-bromatológica da silagem do terço superior da rama de mandioca. Acta Scientiarum, v.26, p.137-146, 2004.

NOGUEIRA, Ú.T.; MAURÍCIO, R.M.; GONÇALVES, L.C.; PEREIRA, L.G.R. Predição da degradação da matéria seca pelo volume de gases utilizando a técnica in vitro semi-automática de produção de gases. Arq. Bras. Med. Vet. Zootec., v.58, p.901-909, 2006.

PEREIRA, E.S.; MIZUBUTI, I.Y.; PINHEIRO, S.M. et al. Avaliação da qualidade nutricional de silagens de milho (Zea mays, L). Caatinga, v.20, p.08-12, 2007.

SÁ, J.F. Avaliação nutricional de alimentos para ruminantes. 2007. 70f. Dissertação (Mestrado em Zootecnia) - Universidade Estadual do Sudoeste da Bahia, Itapetinga.

SCHOFIELD, P.; PELL, A.N. Validity of using accumulated gas pressure reading to mensure forage digestion in vitro: A comparison involving three forages. J. Dairy Sci., v.78, p.2230-2238, 1995.

SCHOFIELD, P.; PITT, R.E.; PELL A.N. Kinetcs of fiber digestion from in vitro gas production. J. Anim. Sci., v.72, p.2980-2991, 1994.

SNIFFEN, C.J.; O'CONNOR, J.D.; VAN SOEST, P.S. et al. A net carbohydrate and protein system for evaluating cattle diets. II. Carbohydrate and protein avaliability, J. Anim. Sci., v.70, p.3562-3577, 1992. 
STATISTICAL Analysis System-SAS. Software, version 6.0. Cary: SAS Institute, 1996.

THEODOROU, M.K.; WILLIAMS, B.A.; DHANOA, M.S.; MCALLAN, A.B. A simple gas production method using a pressure transducer to determine fermentation kinetics of ruminant feeds. Anim. Feed Sci. Technol., v.48, p.185-197, 1994.

TOMICH, T.R.; GONÇALVES, L.C.; MAURÍCIO, R.M. et al. Composição bromatológica e cinética de fermentação ruminal de híbridos de sorgo com capimsudão. Arq. Bras. Med. Vet. Zootec., v.55, p.747-755, 2003.
VAN SOEST, P.J. Nutrition ecology of the ruminant. 2nd ed. Ithaca: Cornell University Press, 1994. 476p.

VELHO, J.P. Qualidade nutritiva de silagens de milho (Zea mays L.) "safrinha" de planta inteira submetida a diferentes maturidades submetidos a distintos procedimentos de ensilagem e "desensilagem". 2005. 147f. Dissertação (Mestrado em Zootecnia) Universidade Federal do Rio Grande do Sul, Santa Maria. 